\title{
Parental Rejection, Personality Maladjustment and Depressive Symptoms in Female Adolescents in Pakistan
}

\author{
${ }^{1}$ Fauzia Naz, ${ }^{2}$ Rukhsana Kausar \\ ${ }^{I}$ Assistant Professor, Visiting Faculty*, \\ ${ }^{2}$ Chairperson, *Department of Applied Psychology, University of the Punjab, Lahore, Pakistan.
}

\begin{abstract}
Depressive symptoms in adolescents are matter of concern because of its high prevalence and impairment of functioning in the affected individual. Present research was conducted to examine parental rejection effect on personality maladjustment and depressive symptoms in female adolescents in Pakistan. 100 female adolescents $(M=16.03, S D=1.74)$ with minor medical conditions were recruited from thee different hospitals. Parental Acceptance-Rejection Questionnaire (Rohner 2005), Personality Assessment Questionnaire (Rohner, 2005) and Centre for Epidemiological Studies Depression Scale (CES-D; Radloff, 1977) were used to assess parental rejection, personality maladjustment and depressive symptoms respectively. Results revealed that parental rejection had significant positive correlation with personality maladjustment and depressive symptoms. Significant positive relationship was found between parental rejection, personality maladjustment and depressive symptoms in adolescents. Personality Maladjustment and parental rejection emerged as significant predictors of depressive symptoms in adolescents. Implications of the findings for parents, health professionals and policy makers are discussed in the context of Pakistani culture.
\end{abstract}

Keywords: Parental rejection, personality maladjustment, depressive symptoms, adolescents

\section{Introduction}

Parental rejection is considered an important factor for psychological, behavioral and developmental problems of children, adolescents, and adults. Research findings proved that perceived parental rejection has been correlated with development of several psychopathologies including personality maladjustment and depression in adolescents (Rohner, 1986). Researches has well established the relationship and association of parental rejection and depressive symptoms in adolescents (Lefkowitz \& Tesiny, 1984; Puig-Antich, Lukens, Davies, Goetz, Quattrock, \& Todak, 1985) and in children. Puig-Antich et al. found higher rejection from mothers of six to twelve years old depressed children in comparison with the non-depressed children.

Researchers (Lefkowitz \& Tesiny, 1984) found positive correlation between maternal rejection and depression as assessed by mother, peer and self. The researchers also argued that paternal rejection predicted depression in daughters in future but not sons. Using the similar constructs like rejection and depression, Wichstrom, Anderson, Holte, and Wynne (1996) investigated harmful interpersonal relations concerning perceived rejection of children's thoughts, emotions and perceptions and its relation with depression and deterioration in general functioning of these children. These researchers found higher level of psychological distress and impaired global functioning in children who were subjected to negative interpersonal communications. Negative interpersonal communication between parents and children is widely studied by Rohner, Khaleque \& Cournoyer (2007) who presented parental acceptance-rejection theory (PARTheory).

PARTheory argues that parental rejection in child's life bring to bear significant impact on the development of child's personality. Children are disapproved by rejecting parents as these parents are likely to impart emotional rejection and give hard punishment which are significant risk factors for developing psychopathology in adolescents (Barnow, Lucht, \& Freyberger, 2001). Parents are important in shaping and maintenance of interpersonal communication with children which exert controlling and molding influences on each other. For long, researches have been reported the relationship between parental behavior and deviation in adolescents (Simons, Robertson, \& Downs, 1989). Scott, W. A., Scott, R., and McCobe (1991) describes that parental aggression, hostility, neglect and rejection were the major variables in the history of adolescents with behavioral problems.

Rohner's theory is supported by Baron and MacGillivray (1989) who investigated relationship between perceived rejection from parents and depressive symptoms in adolescents. They found father's rejection as the most powerful predictors of depressive symptoms in these adolescents. Similarly, Hammen (2005) reported childhood parental rejection as the strongest predictor of depression in adults and adolescents. Some researchers noted relationship between parental rejection and depression as well as with maladjusted behavior in adolescents. Najam and Kausar (2012) found that father's rejection had significant positive relationship with hostility, depression and conduct problems in adolescents. The researchers also found that fathers' involvement 
had inverse correlation with the depression, hostility, dependency, negative self esteem, negative self adequacy, emotional unresponsiveness and negative world view in adolescents in Pakistan.

In the same directions, Lefkowitz and Tesiny (1984) found the relation of childhood parental rejection and depression in childhood and in young adulthood in a series of three studies. They found that death of single or both parents, parental rejection and interparental disharmony were the major etiological risk factors in developing depression in adulthood.

Agnew (2003) describes adolescence as a phase of stress, conflict and detachment between parents and a child. During adolescence period, the child wants autonomy and shows rebellious behavior. If they feel rejection from their parents, they develop different maladjusted behaviors resulting in hostility, aggression, negative worldview and depression (Khaleque \& Rohner, 2002; Sentse, Lindenberg, Omvlee, Ormel, \& Veenstra, 2009). Researches show high associations between adolescents' emotional, behavioral internalizing problems, depression, maladjustment and rejection from parents (Fotti, Katz, Afifi, \& Cox, 2006). Greenberger, Chen, Tally and Dong (2000) also suggested that parental rejection has been associated and implicated in the development of depression and psychological problems. Some researchers (Greenberger \& Chen, 1996) suggest that depression as a result of parental rejection is more common in female adolescents in comparison with the male adolescents. It is also to be noted that parental rejection is associated with the depression in the individuals of any age.

These results are also supported and confirmed by some longitudinal researches which show that parental rejection especially during childhood is associated with depression in adolescents (Robertson \& Simons, 1989). Ge, Lorenz, Conger, Elder, and Simons (1994) argue that perceived rejection from parents is the significant factor in developing depression in both children and adolescents. Depressive symptoms are intertwined with different behavior related abnormalities. These views are supported by Rothbaum and Weiz (1994) in meta analysis of forty-seven researches. The researchers found robust association between parental rejection and children's externalizing behavior i.e., hostility, aggression and non-compliance behavior.

Rejection from parents is found to be negatively associated with the behavioral problems of children.

The researchers also found aggression, anger and impaired self-esteem as significant risk factor as a result of parental rejection (Robertson \& Simons, 1989). These researchers suggested that parental rejection exert greater influence in determining children and adolescents' behavior. Negative parenting and rejection are major variables that influence the development of children and their mental and psychological health during adolescence and adulthood (Yoshizumi, Murase, Murakami, \& Takai, 2007). Shedler and Block (1990; as cited in Rohner et al., 2007) argued that parental rejection has an association and predict personality problems and behavioral problems in children. These problems include poor interpersonal communication with peer, emotional distress, depression and insecurity feelings in children.

Pakistan is a developing country in which boys are given preferences to girls in almost every aspect of life especially in lower socio-economic class in the society. Parents consider girls as a burden for family. They prefer having boys as contributor in the income of family, to handle family affairs and to carry forward the name of the family. They feel pressure by raising girls, to educate them and to manage dowry for their marriage. So, may be in the context of this scenario, they develop, hostility, aggression and rejection towards their daughters.

As reported by Hanif (1994), children belonging to low socio-economic status were more abused as compared to the children from middle and upper socio-economic status in Pakistan. Malik (2012) found typical Pakistani familial context in her research and found high authoritarian attitude of fathers towards children. She found that severely abused children perceived their parents to be rejecting. She also found psychological/emotional abuse more than physical abuse. Najam and Kausar (2012) explored relationship of father acceptance-rejection and involvement with socio-emotional adjustment of adolescents in Pakistan. They found significant negative relationship of paternal warmth with adolescent hostility, dependency, negative selfesteem, negative world-view and depressive symptoms. Father's hostility and rejection had significant positive relationship with hostility, depression and conduct problems in adolescents. Father involvement had significant negative relationship with adolescent hostility, dependency, negative self esteem, negative self adequacy, emotional unresponsiveness, negative world view and depression in adolescents. The researchers found that rejection from father, adolescent dependency and emotional instability emerged as significant predictors of depression in adolescents. Father's hostility and lack of involvement emerged as significant predictors of conduct problems in adolescents.

It is concluded that parental rejection is a major factor in development of maladjusted personality as well as psychopathology i. e., depressive symptoms in adolescents. The query of association between parenting style and personality maladjustment combined with depressive symptoms has not received much attention yet by researchers in Pakistan. The main objective of our research was to explore relationships between parental rejection, personality maladjustment and depressive symptoms. Further, the research also aimed to explore different dimensions of parental rejection as a predictor of personality maladjustment. Finally, the research 
explored different dimensions of parental rejection and different dimensions of personality maladjustment as predictors of depressive symptoms in adolescents.

Hypotheses: The following hypotheses were made

a) Parental rejection, personality maladjustment and depressive symptoms are likely to be positively correlated in adolescents.

b) Parental rejection is likely to predict personality maladjustment in adolescents.

c) Different dimensions of parental rejection i.e., coldness/lack of affection, hostility/aggression, indifference/neglect, undifferentiated/rejection and control and different dimensions of personality maladjustment i.e., hostility/aggression, dependency, negative self-esteem, negative self-adequacy, emotional unresponsiveness, emotional instability and negative worldview are likely to predict depressive symptoms in adolescents.

\section{Method}

Sample: One-hundred female adolescents with minor medical conditions were recruited from the departments of general outdoor patients of three different hospitals of Lahore, Pakistan. Minor medical conditions mean the adolescents were suffering from fever, cough, throat infection and flue. In Pakistan, the medical treatment in hospitals is totally free for people. Most of the people who benefit from free treatment in these hospitals belong to lower-socio-economic class or lower middle socio-economic class. The girls were recruited from these outdoor departments after making sure that they belong to homogenous family and socioeconomic background. The age range of the adolescents was between 13 to 18 years (Mean age $=16.00$ years). Demographic characteristics of the sample are presented in table 1.

Table 1. Demographic Characteristics of Sample $(N=100)$.

\begin{tabular}{lll}
\hline Variables & $M$ & $S D$ \\
\hline Age & 16.00 & 8.63 \\
Father's age & 45.03 & 4.18 \\
Mother's age & 42.82 & 4.37 \\
Monthly family income (Pakistani Rupees) & 13525 & 5608 \\
& $F$ & $\%$ \\
Education Grade 6-8 & 31 & 31 \\
Education Grade9-10 & 34 & 34 \\
Education Grade 11-12 & 28 & 28 \\
Education Continued & 72 & 72 \\
Education Discontinued & 28 & 28 \\
Joint Family System & 73 & 73 \\
Nuclear Family System & 27 & 27 \\
Birth Order & & \\
$1^{\text {st }}$ & 25 & 25 \\
$2^{\text {nd }}$ & 25 & 39 \\
$3^{\text {rd }}$ & 39 & 27 \\
$4^{\text {th }}-7^{\text {th }}$ & 27 & 9 \\
\hline
\end{tabular}

\section{Ethical Considerations}

Permission from the authors of assessment tools was obtained to use and translate the assessment measures for the present research. For data collection, permission was gained from the respective heads of General Outdoor Patients Departments of the hospitals. Participants and their parents/guardians informed consent was obtained to take part in the study. Participants were assured about the confidentiality of the information provided by them.

\section{Procedure}

The assessment measures were translated into Urdu language (National language of Pakistan) after taking permission from authors. After taking approval from IRB, we recruited the female adolescent with minor medical conditions from the General outdoor Departments of three public sector hospitals from Lahore, Pakistan. The adolescents and their parents/guardians were given detailed information about the aims of research and they were provided with informed consent forms. After taking informed consent from the participants/parents, the process of assessment was carried out. The assessment procedure was carried out in a separate room. Parents were not allowed to accompany the adolescents where the assessment procedure was taken place. Total 130 girls were approached in which twenty girls refused to take part in study. Ten girls left much information blank while filling the assessment measures so these ten girls were also excluded. After the completion of assessment measures from sample, data of 100 girls were analyzed and results were calculated. 


\section{Assessment Measures}

Demographic Information Questionnaire: A demographic questionnaire was used to take the sociodemographic information from participants. This questionnaire included all relevant demographic variables such as age, education status (continued or discontinued), education, parental education, age and occupation, family type and family system.

Parental Acceptance-Rejection Questionnaire; child (PARQ: Child) PARQ child (mother; father) is a self-report scale and consisted in 29 items. This scale measures child's perception of paternal and maternal acceptance-rejection separately. The scale consists of five sub-scales which measure paternal or maternal coldness/lack of affection, indifferent/neglect, undifferentiated/rejection and control. The questionnaire is developed and revised by Rohner and Khaleaque (2005). Rohner described sufficient alpha reliability of the scale that is .82. The four options for the rating are almost never true (1), rarely true (2), sometimes true (3), almost always true (4). Item number 1, 4, 11, 15, 16, 20, 21, 23, 27 and 29 requires reverse scoring. Scores on these items after reverse scoring create a measure of perceived coldness and lack of affection. The overall measure of perceive rejection score ranges from a low of 29 to a high of 116 (perceived rejection from mother and father). In the present research the sub-scale control was not computed because we were only interested to measure rejection from parents. The scale has separate scores for mothers' and fathers' acceptance and rejection.

Before starting the research, permission to use and translate the scale into the Urdu language was taken from the author via e-mail. PARQ child was translated into Urdu language, the Pakistani National Language. Internal consistency for the present research was .89 for the mother version and .90 for the father version.

Personality Assessment Questionnaire (PAQ; Rohner \& Khaleaque, 2005). It is a self-report measure consisted in 42 items. PAQ assesses individual perception about themselves. It comprises of seven sub-scales i.e., hostility and aggression, dependency, negative self-esteem, negative self-adequacy, emotional unresponsiveness, emotional instability and negative worldview. Collectively, the seven PAQ sub-scales represent a measure of respondents' overall psychological maladjustment. The higher a total-test score (168), the more impaired an individual's psychological adjustment is regarded to be (Rohner, 2005). Four options for the rating are almost never true (1), rarely true (2), sometimes true (3), almost always true (4). Item numbers 3 , $4,7,10,12,16,18,21,24,26,31,34,39,40$ and 42 requires reverse scoring. The scale was translated into Urdu language for using in the present research. Cronbach's alpha computed for the current sample of the study for PAQ was highly significant $(=.94)$.

Centre for Epidemiological Studies for Depression Scale (CES-D). This scale consists of 20 statements with four options that are rarely or none of the time (less than 1 day), some or a little of the time (for 1-2 days), occasionally or a moderate amount of time (for 3-4 days) and all of the time (for 5-7 days). Item No. 4, 8, 12 and 16 are reverse items. The statements describe the way one have felt or behaved during the past week. A cut-off score of 16 or greater is considered depression. Internal consistency reliability is .90 (Radloff, 1977). In this research, CES-D was used after getting it translated into Urdu language. Internal consistency of the scale for the present study was very good that is .93.

\section{Results}

Results were calculated by using (a) Pearson Product-Moment Correlation to see the relationship between parental rejection, personality maladjustment and depressive symptoms, (b) regression analyses to see the parental rejection as a predictor of personality maladjustment, (c) regression analyses to see the parental rejection and personality maladjustment in combination as predictors of depressive symptoms. The results related to correlation are presented in table 2.

Table 2 Relationship between Parental Rejection, Personality Maladjustment and Depressive Symptoms

\begin{tabular}{|c|c|c|c|c|c|c|c|c|c|}
\hline Variables & $\begin{array}{l}\mathrm{H} / \mathrm{A} \\
\text { (PAQ) }\end{array}$ & $\begin{array}{l}\text { Dep } \\
\text { (PAQ) }\end{array}$ & $\begin{array}{l}\text { NSE } \\
\text { (PAQ) }\end{array}$ & $\begin{array}{l}\text { NSA } \\
\text { (PAQ) }\end{array}$ & $\begin{array}{l}\text { EU } \\
\text { (PAQ) }\end{array}$ & $\begin{array}{l}\text { EI } \\
(P A Q)\end{array}$ & $\begin{array}{l}\text { NWV } \\
\text { (PAQ) }\end{array}$ & $\begin{array}{l}\text { Total } \\
\text { PAQ }\end{array}$ & $\begin{array}{l}\text { Depressive } \\
\text { Symptoms }\end{array}$ \\
\hline PARQ Mother & & & & & & $.67 * *$ & $.63 * *$ & $.73 * *$ & $.53 * *$ \\
\hline Coldness & $.61 * *$ & $.23 * *$ & $.62 * *$ & $.70 * *$ & $.71 * *$ & & & & \\
\hline Hostility/Aggression & $.57 * *$ & $.16^{*}$ & $.51 * *$ & $.57 * *$ & $.57 * *$ & $.54 * *$ & $.49 * *$ & $.61 * *$ & $.34 * *$ \\
\hline Indifferent/Neglect & $.57 * *$ & $.16^{* *}$ & $.56 * *$ & $.64 * *$ & $.64 * *$ & $.68 * *$ & $.55 * *$ & $.67 * *$ & $.60 * *$ \\
\hline Undiff/Rejection & $.57 * *$ & .09 & $.49 * *$ & $.58 * *$ & $.59 * *$ & $.57 * *$ & $.52 * *$ & $.61 * *$ & $.29 * *$ \\
\hline Total & $.63 * *$ & $.23 * *$ & $.61 * *$ & $.69 * *$ & $.70 * *$ & $.70 * *$ & $.61 * *$ & $.73 * *$ & $.62 * *$ \\
\hline \multicolumn{10}{|l|}{ PARQ Father } \\
\hline Coldness & $.60 * *$ & $.21 * *$ & $.58 * *$ & $.70 * *$ & $.74 * *$ & $.68^{* *}$ & $.62 * *$ & $.73 * *$ & $.56^{* *}$ \\
\hline Hostility/Aggression & $.58 * *$ & $.21 * *$ & $.48 * *$ & $.60 * *$ & $.59 * *$ & $.55 * *$ & $.55 * *$ & $.64 * *$ & $.27 * *$ \\
\hline Indifferent/Neglect & $.54 * *$ & $.21 * *$ & $.51 * *$ & $.63 * *$ & $.62 * *$ & $.63 * *$ & $.54 * *$ & $.65^{* *}$ & $.54 * *$ \\
\hline Undiff/Rejection & $.67 * *$ & $.20 * *$ & $.49 * *$ & $.67 * *$ & $.66 * *$ & $.61 * *$ & $.55 * *$ & $.69 * *$ & $.32 * *$ \\
\hline Total & $.67 * *$ & $.26^{* *}$ & $.58^{* *}$ & $.73 * *$ & $.75^{* *}$ & $.70 * *$ & $.63 * *$ & $.77 * *$ & $.55^{* *}$ \\
\hline
\end{tabular}


$* * P<0.01, * P<0.05$

Note H/A, Hostility/Aggression PAQ: Dep: Dependency, NSE: Negative Self-Esteem, NSA: Negative SelfAdequacy, EU: Emotional Unresponsiveness, EI: Emotional Instability, NWV: Negative Worldview

Results show significant positive relationship between different sub-scales of parental rejection and different dispositions of personality i.e., coldness, hostility/aggression, indifferent/neglect and undifferentiated/rejection and total rejection (PARQ; father, mother) showed significant positive relationship with hostility/aggression (PAQ), dependency (PAQ), negative self-esteem (PAQ), negative self-adequacy (PAQ), emotional unresponsiveness (PAQ), emotional instability (PAQ), negative worldview (PAQ) and total PAQ. Results also revealed significant positive relationship between parental rejection, personality maladjustment and depressive symptoms in adolescents.

The results related to regression analyses to see the parental rejection as a predictor of personality maladjustment are presented in table 3 .

Table 3

Multiple Regression Analyses (forward entry) for Parental Rejection as predictors of Maladjusted Personality $(N=100)$

\begin{tabular}{|c|c|c|c|c|c|c|c|}
\hline Outcome Variables & & Predictors & $\overline{\Delta R^{2}}$ & $\begin{array}{l}R^{2} \\
\text { Chang } \\
\mathrm{e}\end{array}$ & $F$ & $B$ & $t$ \\
\hline \multirow[t]{2}{*}{ Hostility/Aggression } & 1 & Undifferentiated/Rejection (father) & .45 & & $165.00 * *$ & .67 & $12.84 * *$ \\
\hline & 2 & $\begin{array}{l}\text { Undifferentiated/Rejection (father) } \\
\text { Coldness/lack of affection (mother) }\end{array}$ & .50 & .05 & $102.38 * *$ & .30 & $4.70 * *$ \\
\hline \multirow[t]{3}{*}{ Dependency } & 1 & Coldness/lack of affection (mother) & .04 & & $11.12 * *$ & .23 & $3.33 * *$ \\
\hline & 2 & $\begin{array}{l}\text { Coldness/lack of affection (mother) } \\
\text { Undifferentiated/Rejection (mother) }\end{array}$ & .06 & & $8.31^{* *}$ & .26 & $2.29 *$ \\
\hline & 3 & $\begin{array}{l}\text { Coldness/lack of affection (mother) } \\
\text { Undifferentiated/Rejection (mother) } \\
\text { Hostility/Aggression (father) }\end{array}$ & .08 & .02 & $7.37 * *$ & .19 & $2.26 *$ \\
\hline \multirow{2}{*}{$\begin{array}{l}\text { Negative } \\
\text { Esteem }\end{array}$} & 1 & Coldness/lack of affection(mother) & .38 & & $126.61 * *$ & .62 & $11.25 * *$ \\
\hline & 2 & $\begin{array}{l}\text { Coldness/lack of affection(mother) } \\
\text { Coldness/lack of affection (father) }\end{array}$ & .42 & .03 & $73.81 * *$ & .28 & $3.36^{* *}$ \\
\hline \multirow{3}{*}{$\begin{array}{l}\text { Negative } \\
\text { Adequacy }\end{array}$} & 1 & Coldness/lack of affection (father) & .49 & & $194.45 * *$ & .70 & $13.94 * *$ \\
\hline & 2 & $\begin{array}{l}\text { Coldness/lack of affection (father) } \\
\text { Coldness/lack of affection(mother) }\end{array}$ & .56 & & $131.08 * *$ & .40 & $5.88 * *$ \\
\hline & 3 & $\begin{array}{l}\text { Coldness/lack of affection (father) } \\
\text { Coldness/lack of affection(mother) } \\
\text { Undifferentiated/Rejection (father) }\end{array}$ & .60 & .03 & $100.54 * *$ & .27 & $4.18^{* *}$ \\
\hline \multirow{3}{*}{$\begin{array}{l}\text { Emotional } \\
\text { Unresponsiveness }\end{array}$} & 1 & Coldness/lack of affection (father) & .55 & & $252.91 * *$ & .74 & $15.90 * *$ \\
\hline & 2 & $\begin{array}{l}\text { Coldness/lack of affection (father) } \\
\text { Coldness/lack of affection(mother) }\end{array}$ & .61 & & $161.57 * *$ & .31 & $5.60 * *$ \\
\hline & 3 & $\begin{array}{l}\text { Coldness/lack of affection (father) } \\
\text { Coldness/lack of affection(mother) } \\
\text { Undifferentiated/Rejection (father) }\end{array}$ & .63 & & $115.60 * *$ & .17 & $3.09 * *$ \\
\hline \multirow[t]{3}{*}{ Emotional Instability } & 1 & Indifferent/neglect (mother) & .46 & & $172.29 * *$ & .68 & $13.12 * *$ \\
\hline & 2 & $\begin{array}{l}\text { Indifferent/neglect (mother) } \\
\text { Coldness/lack of affection (father) }\end{array}$ & .55 & & $122.72 * *$ & .40 & $6.29 * *$ \\
\hline & 3 & $\begin{array}{l}\text { Indifferent/neglect mother } \\
\text { Coldness/lack of affection(mother) } \\
\text { Undifferentiated/Rejection (father) }\end{array}$ & .56 & .01 & $86.09 * *$ & .17 & $2.50 * *$ \\
\hline \multirow[t]{2}{*}{ Negative worldview } & $\begin{array}{l}1 \\
2\end{array}$ & $\begin{array}{l}\text { Coldness/lack of affection(mother) } \\
\text { Coldness/lack of affection(mother) } \\
\text { Coldness/lack of affection(father) }\end{array}$ & $\begin{array}{l}.39 \\
.45\end{array}$ & & $\begin{array}{l}130.22 * * \\
82.94 * *\end{array}$ & $\begin{array}{l}.63 \\
.35\end{array}$ & $\begin{array}{l}11.41 * * \\
4.68 * *\end{array}$ \\
\hline & 3 & $\begin{array}{l}\text { Coldness/lack of affection(mother) } \\
\text { Coldness/lack of affection(father) } \\
\text { Hostility/aggression (father) }\end{array}$ & .47 & .02 & $60.18 * *$ & .19 & $2.90 * *$ \\
\hline Personality & 1 & Coldness/lack of affection(mother) & .54 & & $236.91 * *$ & .73 & $15.39 * *$ \\
\hline \multirow[t]{2}{*}{$\begin{array}{l}\text { Maladjustment (PAQ } \\
\text { total) }\end{array}$} & 2 & $\begin{array}{l}\text { Coldness/lack of affection(mother) } \\
\text { Coldness/lack of affection (father) }\end{array}$ & .62 & & $166.71 * *$ & .42 & $6.67 * *$ \\
\hline & 3 & $\begin{array}{l}\text { Coldness/lack of affection (father) } \\
\text { Coldness/lack of (mother) } \\
\text { Undifferentiated/Rejection (father) }\end{array}$ & .65 & .03 & $126.54 * *$ & .25 & $4.21 * *$ \\
\hline
\end{tabular}

Note. PARQ: Parental Acceptance-Rejection Questionnaire, PAQ: Personality Assessment Questionnaire. 
Regression analyses show that undifferentiated rejection (father) and coldness/lack of affection (mother) emerged as significant predictors of hostility/aggression (PAQ) in adolescents. These variables accounted fifty percent of the variance. For dependency (PAQ), coldness/lack of affection (mother), undifferentiated rejection (mother) and hostility/aggression (father) emerged as significant predictors. These variables accounted for eight percent of the variance. For the third dimension of PAQ i.e., negative self-esteem, the significant predictors were coldness/lack of affection (mother, father) emerged as significant predictors of negative self-esteem. These variables accounted for forty-two percent of the variance. Coldness/lack of affection (father, mother) and undifferentiated rejection (father) emerged as significant predictors of negative selfadequacy accounting for sixty percent of the variance. For emotionally unresponsiveness, coldness/lack of affection (father, mother) and undifferentiated rejection (father) emerged as significant predictors accounting sixty-three percent of the variance. Indifferent/neglect (mother) and coldness/lack of affection (father) emerged as significant predictors of emotional instability. These variables accounted for fifty-six percent of the variance. For the dimension of negative worldview, coldness/lack of affection (mother, father) and undifferentiated/rejection (father) emerged as significant predictors accounting forty-seven percent of the variance. For PAQ total, regression analyses worked out in three steps. Coldness/lack of affection (father, mother) and undifferentiated rejection (father) emerged as significant predictors accounting sixty-five percent of the variance.

Table 4 shows the results of regression analyses which was performed to see the parental rejection and personality maladjustment in combination as predictors of depressive symptoms.

Table 4Multiple Regression Analyses (forward entry) for Parental Rejection and Personality Maladjustment as Predictors of Depressive Symptoms $(N=100)$

\begin{tabular}{|c|c|c|c|c|c|c|c|}
\hline $\begin{array}{l}\text { Outcome } \\
\text { Variables }\end{array}$ & & Predictor & $\Delta R^{2}$ & $\begin{array}{l}R^{2} \\
\text { Change }\end{array}$ & $F$ & $\beta$ & $t$ \\
\hline \multirow{7}{*}{$\begin{array}{l}\text { Depressive } \\
\text { Symptoms }\end{array}$} & 1 & Negative self-adequacy (PAQ) & .62 & & $335.09 * *$ & .79 & $18.30 * *$ \\
\hline & 2 & $\begin{array}{l}\text { Negative self-adequacy (PAQ) } \\
\text { Coldness/lack of affection(mother) }\end{array}$ & .68 & & $221.32 * *$ & .35 & $6.37 * *$ \\
\hline & 3 & $\begin{array}{l}\text { Negative self-adequacy (PAQ) } \\
\text { Coldness/lack of affection(mother) } \\
\text { Negative self-esteem (PAQ) }\end{array}$ & .71 & & $163.18 * *$ & .23 & $3.89 * *$ \\
\hline & 4 & $\begin{array}{l}\text { Negative self-adequacy (PAQ) } \\
\text { Coldness/lack of affection(mother) } \\
\text { Negative self-esteem (PAQ) } \\
\text { Dependency (PAQ) }\end{array}$ & .72 & & $128.83^{* *}$ & .11 & $2.84 * *$ \\
\hline & . & $\begin{array}{l}\text { Negative self-adequacy (PAQ) } \\
\text { Coldness/lack of affection(mother) } \\
\text { Negative self-esteem (PAQ) } \\
\text { Dependency (PAQ) } \\
\text { Indifference/neglect (father) }\end{array}$ & .72 & & $107.49 * *$ & .13 & $2.60 * *$ \\
\hline & 6 & $\begin{array}{l}\text { Negative self-adequacy (PAQ) } \\
\text { Coldness/lack of affection(mother) } \\
\text { Negative self-esteem (PAQ) } \\
\text { Dependency (PAQ) } \\
\text { Indifference/neglect (father) } \\
\text { Coldness/lack of affection(father) }\end{array}$ & .73 & & $93.44 * *$ & .18 & $2.62 * *$ \\
\hline & 7 & $\begin{array}{l}\text { Negative self-adequacy (PAQ) } \\
\text { Coldness/lack of affection(mother) } \\
\text { Negative self-esteem (PAQ) } \\
\text { Dependency (PAQ) } \\
\text { Indifference/neglect (father) } \\
\text { Coldness/lack of affection(father) } \\
\text { Negative Worldview (PAQ) }\end{array}$ & .74 & .00 & $81.87^{* *}$ & .13 & $1.98 * *$ \\
\hline
\end{tabular}

Regression analyses show that negative self-adequacy (PAQ), coldness/lack of affection (father), negative self-esteem (PAQ), dependency (PAQ), indifference/neglect (father) and coldness/lack of affection (father) and negative worldview (PAQ) emerged as significant predictors of depressive symptoms in adolescents. These variables accounted seventy-four percent of the variance. 
Figure: 1 Model Emerged after Regression Analyses

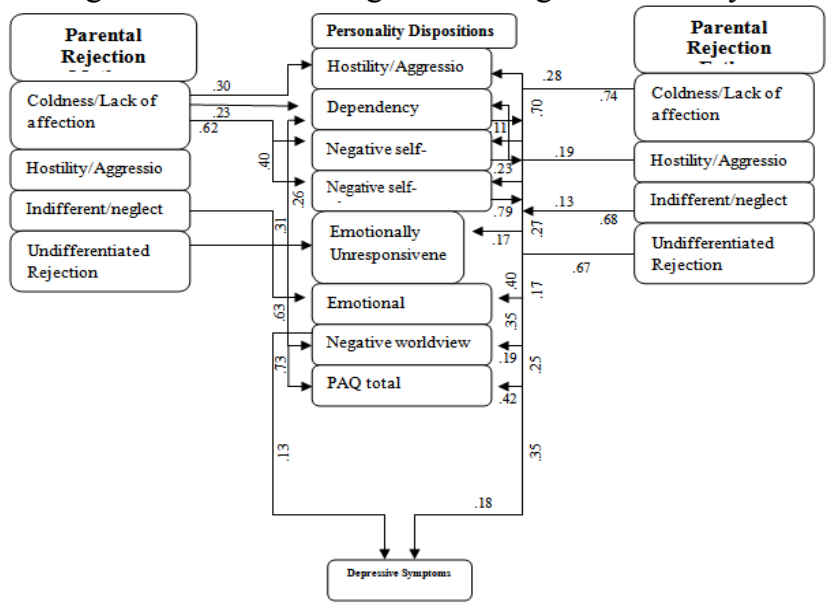

\section{Discussion}

Present study examined the relationship between rejection from parents, personality maladjustment and depressive symptoms in female adolescents in general population in Pakistan. In addition, parental rejection and personality maladjustment were also explored as predictors of depressive symptoms in female adolescents.

In our research, results show significant positive relationship between parental rejection (both father \& mother), personality maladjustment and depressive symptoms in adolescents. Results also showed that different sub-scales of parental rejection emerged as significant predictors of different sub-scales of personality. These sub-scales included hostility/aggression, dependency, negative self-esteem, negative self-adequacy, emotional unresponsiveness, emotional instability and negative worldview. We explain the results through personality subtheory of PARTheory which describes that environment and subjective factors influence behavior. These factors lead to the personality outcomes that include hostility, aggression, emotional unresponsiveness, immature dependence, impaired self-esteem, impaired self-adequacy, emotional instability and negative worldview.

According to this theory, if adolescents experience negative life events especially interpersonal trauma (rejection from parents), this will lead to develop personality maladjustment as well as psychopathology in future (Rohner et al., 2007). Thus, perceived rejection by a child postulates high effects on adolescents' psychological and personality adjustment. Parental rejection leads to develop negative personality outcomes. These negative personality outcomes tend to reduce rejected children's capacity to handle successfully with stresses. Consequently, these children develop depressive symptoms and other behavior problems. Our results are in agreement with those of Sassaroli and Ruggiero's (2005) research who reported that low self-esteem, tension and critical attitude of parents were significantly associated with the development of adult psychopathology.

In our research, rejection from father and coldness from mother emerged as significant predictors of hostility/aggression (PAQ) in adolescents. Results have shown that coldness/lack of affection from mother, rejection from mother and hostility and aggression from father rejection from father emerged as significant predictor of dependency in adolescents. Dependency as Rohner and Khaleque (2005) describes, refers to feelings of psychological wish for emotional support from parents. Dependent children have intense desire for positive response. Rejected children are likely to develop feelings of insecurity which make them more dependent. These results are supported by a research by Najam and Kausar (2012) in which the researchers found significant negative relationship of paternal warmth with adolescents' dependency and depressive symptoms. They also found father's rejection had significant positive relationship with hostility, depression and conduct problems in adolescents. Father involvement had negative relationship with adolescent hostility, dependency, negative self esteem, negative self adequacy, emotional unresponsiveness, negative world view and depression in adolescents.

Next, rejection from father, adolescent dependency and emotional instability emerged as significant predictors of depressive symptoms in adolescents. These results are in line with the research by Barnow and colleagues (2001) who reported that negative interpersonal communication, abusive behavior of parents and family circumstances was highly correlated with the aggression in children and in adolescents.

These results are consistent with PARTheory (Rohner \& Khaleque, 2005) which describes that rejection by parents has a decisive impact on child's personality development. The rejecting parents dislike and disapprove their children. These negative attitudes from parents like rejection and severe punishment are risky in creating violence and aggression in adolescents (Barnow et al., 2001). Rohner in a sub-section of PARTheory that is personality sub-theory, describes that child's awareness of emotional health and security is correlated 
with perceived rejection from parents. So, parental rejection postulates to contribute negative effects on children's psychological adjustment.

Results from the present research are also in line with the research done in Pakistan by the researchers (Riaz \& Qasmi, 2012) who explored the impact of parental rejection on the psychological adjustment of children. The researchers also explores these variables in youth with physical, hearing and visual disabilities.

The results show severe psychological maladjustment in children as well as in youth. Likewise, the results show that coldness from father as well as mother emerged as significant predictors of negative selfesteem in adolescents. Self-esteem is described as the individuals' feelings about self-value or self-worth (Rohner and Khaleque. 2005). These findings are in agreement with those of Barnow et al., (2001) who in their research found family circumstances and highly negative and abusive behavior had strong correlation with aggression, negative self-concept, impaired self-esteem, unhappiness and impaired capacity to trust others and difficulties in communication with peer and other persons (Ounsted, Oppenheimer, \& Lindsey, 1974).

Additionally, the findings show that coldness and lack of affection from both parents and rejection from father were significant predictors of negative self-adequacy in adolescents. Self-inadequacy contains as developing incompetence to complete daily tasks properly and failure to satisfy one's own requirements. Results from the present research are confirm PARTheory which states that negative self-adequacy emerges as a result of chronic psychological pain produced by perceived parental rejection, aggression and childhood physical abuse (Rohner et al., 2007). Gurarino, Guttman, and Seeley (1986; as cited in Rohner et al., 2007) agree with Rohner and colleagues that rejecting attitude on the part of parents can create maladjusted personality of the child.

Fergusson and Mullen (1999) reported that negligence from fathers in the form of absence create aggression, hostility and rejection. These fathers fail to give the necessary care that would buffer against longterm health effects. In a research study, Fuyi and Ningjian (2008) examined the influence of early experiences on adolescents' self-esteem. The results indicated that adolescents from divorced families had lower implicit self-esteem than those from intact families. They found significant positive correlation between adolescents' implicit self-esteem and their parents' "emotional warmth and understanding" and their mothers' "favoritism".

This suggests positive parenting styles could enhance adolescents' implicit self-esteem. The results from their research also revealed that parents' rejection and negating and mothers' punishment were significantly related to the discrepancy between adolescents' s covert self-esteem and overt self-esteem. They concluded that that negative parenting styles affected the consistency of adolescents' covert self-esteem and overt self-esteem.

These results are in line with the research in which Anne (1998) examined the impact of the quality of attachment in female adolescents to parents and its after-effect on shaping self-esteem and developing psychopathology. The researcher demonstrated high significant differences on self-esteem, depression, anxiety and emotional autonomy between female adolescents who had high parental security and those with low parental security. Findings from this research demonstrate that girls adolescents who had high parental security feelings had low emotional autonomy, low depression and anxiety, and higher levels of self-esteem. These results proved that girls with high parental security had less depressive symptoms and higher self-esteem. These findings suggest that female adolescents' secure attachment with parents promote more adaptive psychosocial functioning and provided a buffer against negative affect.

In our research, results show that rejection from father, coldness mother and coldness father were significant predictors of emotional unresponsiveness and rejection from father, indifferent/neglect mother, coldness mother were significant predictors of emotional instability in adolescents. Whereas coldness and hostility from father and coldness from mother appeared the significant predictors of negative world view and coldness from father, mother and rejection from father emerged as significant predictors of personality maladjustment (total) in adolescents. These results are in line with the study in which Zhe, Li, Yong-mei, Rong, and Shi-jie (2011) explored relationship between parenting styles and antisocial personality disorder. Findings from their study explained that compared with normal adolescents, those with antisocial personality disorders had experienced less care form their parents, and did not encourage their behavioral freedom, most time controlled during their childhood. Physical abuse, angry to father, motherhood inverse, emotional abuse, mother's coldness and lack of love, and mother's control were predictors of antisocial personality disorder. Childhood abuse and parenting styles have effect on shaping the antisocial personality disorder.

Robertson and Simons (1989) noted that perceived rejection from parents was the strongest risk factor associated with depression and low self-esteem in adolescents. Perceived parental rejection showed effects through low self-esteem. Low self-esteem found to be strongly associated with depressive symptoms. A propensity to blame one self for negative elements was perceived as the cause of vulnerable self-esteem. This self-blaming attributional style may develop in response to a perceived family environment of excessive parental criticism, shaming, and belittling.

Then the model containing different dimensions of parental rejection and personality maladjustment was tested as predictors of depressive symptoms in girls adolescents, it showed that negative self-adequacy (PAQ), 
coldness/lack of affection(mother), Negative self-esteem (PAQ), dependency (PAQ), indifference/neglect (father), coldness/lack of affection(father) and negative worldview (PAQ) appeared as significant predictors.

These results are supported by many of the other researches. Previous research shows that perceived rejection from parents causes psychopathology in adolescents. Rita and Oksana, (2008) found that differences in parental rearing attitude and personality traits (e.g., neuroticism) were stronger predictors of behavioral and emotional problems for girls in comparison to boys. Davidson, Inslicht, and Baum (2000) comment that children's exposure to traumatic events has profound effects on development and well-being. Evidence suggests that children are exposed and react similarly to threatening events and experience mild and severe symptoms of stress. Precipitating events and mediating variables are considered common symptoms of distress along a developmental continuum. The dependent nature of children may put them at greater risk for exposure to some traumatic stressors and may exacerbate the impact of others. General effects of extreme stressors are negative, and many children are resilient in the face of such stress. However, some experience stress and develop poststressor syndromes. Of particular concern among young children is the possibility that trauma can have broader, systemic effects, sensitizing them to stressors, altering belief systems and worldview and affecting their maturational progress in critical development phases.

Savin-Williams (1990) argued that early adolescence is a period when the child is undergoing diverse forms of new behavioral, physical, academic, social and interpersonal challenges and changes. The study of interpersonal relationships within family are important variables to be studied in adolescents. Especially, when adolescents are self conscious and have high concern about the others' attitude about them (Elkind, 1978).

Abramson, Metalsky and Alloy (1989) argue that the experience of perceived rejection from others especially parents is likely to develop bad feelings about oneself and create depression. Thus, a sense of rejection during this time of increasing normative demands could contribute to the increases in depressive symptoms observed during adolescence (e.g., Hankin, Abramson, Moffitt, Silva, McGee, and Harter, 1999).

\section{Conclusion}

In summary, we found that rejection in combination with personality maladjustment significantly predicted adolescents' depressive symptoms over time. The observed prospective relation between rejection and depressive symptoms parallels findings suggesting the importance of interpersonal relationships among adolescents.

\section{Limitations and suggestions for future research}

A limitation was that participants were taken only from low-socio-economic class and from government hospitals. It is suggested that the future research should include participants from other socioeconomic groups and comparison should be made. Future researchers should also recruit sample from private hospitals and clinics. Another limitation was that sample was comprised of girls only. It is suggested that boys should also be included in the sample and gender differences should also be explored regarding these variables.

\section{Implications of research findings}

Present research will be helpful for clinicians and parents with the special reference to Pakistani cultural context to understand the possible links of parental behavior and development of maladjusted personality and depression in girls so that we can see better generation in future.

\section{Acknowledgement}

Note: This research manuscript is a part of first author's Ph. D research.

Acknowledgements: We acknowledge the participants and their parents for their participation in this research work. We also acknowledge Higher Education Commission, Pakistan for funding this research project.

\section{References}

[1]. Abramson, L. Y., Metalsky, G. I., \& Alloy, L. B. (1989). Hopelessness depression: A theory- based subtype of depression. Psychological Review, 96, 358-372.

[2]. Agnew, R. (2003). An integrated theory of the adolescent peak in offending. Youth \& Society, 34, 263-299.

[3]. Akse, J., Hale, W. W., Engels, R. C., Raaijmakers, Q. A., \& Meeus, W. H. (2004). Personality, perceived parental rejection and problem behavior in adolescence. Social Psychiatry and Psychiatric Epidemiology. 39 (12): 980-8.

[4]. Anne, M. R. (1998). Attachment of female adolescents to parents and its effect on self-esteem and depression. Dissertation Abstracts International: The Sciences and Engineering, (pp. 6259).

[5]. Barnow, S., Lucht, M., \& Freyberger, H. (2001). Influence of punishment, emotional; rejection, child abuse, and broken home on aggression in adolescence: An examination of aggressive adolescents in Germany. Psychopathology, 34(4), 167-173.

[6]. Baron, P., \& MacGillivray, R. G. (1989). Depressive symptoms in adolescents as a function of perceived parental behavior. Journal of Adolescent Research, 4, 50-62.

[7]. Coyne, J. C. (1976). Toward an interactional description of depression. Psychiatry, 39, 28-40. 
[8]. Davidson, L. M., Inslicht, S. S., \& Baum, A. (2000). Traumatic stress and posttraumatic stress disorder among children and adolescents. In M. Lewis (Ed.), Handbook of developmental psychopathology (pp. 723-737). New York: Kluwer Academic/Plenum.

[9]. Elkind, D. (1978). Understanding the young adolescent. Adolescence, 49, 127-134.

[10]. Fergusson, D. M., \& Mullen, P. E. (1999). Child sexual abuse: An evidence based perspective. California: Sage Publications.

[11]. Fotti, S. A., Katz, L. Y., Afifi, T. O., \& Cox, B. J. (2006). The associations between peer and parental relationships and suicidal behaviours in early adolescents. Canadian Journal of Psychiatry, 51, 698-703.

[12]. Fuyi, Y., \& Jian, L. N. (2008). Early experience of young people the impact of implicit self-esteem. Psychological Science, 31(3), $556-561$.

[13]. Ge, X., Lorenz, F. O., Conger, R. D., Elder, G. H. Jr., \& Simons, R. L. (1994). Trajectories of stressful life events and depressive symptoms during adolescence. Developmental Psychology, 30, 467-483.

[14]. Greenberger, E., Chen, C., Tally, S. R., \& Dong, Q. (2000). Family, peer, and individual correlates of depressive symptomatology among U.S. and Chinese adolescents. Journal of Consulting and Clinical Psychology, 68, 209-219.

[15]. Greenberger, E., \& Chen, C. (1996). Perceived family relationship and depressed mood in early and late adolescence: A compari son of European and Asian Americans. Developmental Psychology, 32, 707-716.

[16]. Hanif, R. (1994). Behavioral problems of abused and non-abused children. Unpublished M. Phil.

[17]. Dissertation, National Institute of Psychology, Quaid-i-Azam University, Islamabad Hankin, B. L., Abramson, L. Y., Moffitt, T. E., Silva, P. A., McGee, R., \& Harter, S. (1999). The construction of the self: A developmental perspective. New York: Guilford Press.

[18]. Hammen C. (2005). Stress and depression. Annual Review of Clinical Psychology, 1, 293-319.

[19]. Lefkowitz, M. M., \& Tesiny, E. P. (1984). Rejection and depression: Prospective and contemporaneous analyses. Developmental Psychology, 20, 776-785.

[20]. Levitan, R., Rector, N., Sheldon, T., \& Goering, P. (2003). Childhood adversities associated with major depression and/or anxiety disorders in a community sample of Ontario: Issues of comorbidity and specificity. Depression and Anxiety, 17, 34-42.

[21]. Malik, F. (2012). Parental Acceptance-Rejection and Paternal Authoritarianism among Abused Children in Pakistan. Journal of Behavioural Sciences, 22, 23-48.

[22]. Najam, N., \& Kausar (2012). Father acceptance-rejection, father involvement and socio- emotional adjustment of adolescents in Pakistan. Journal of Behavioral Sciences, 22, 1-21.

[23]. Ounsted, C., Oppenheimer, R., \& Lindsey, J. (1974). Aspects of bonding failure: The psychology and psychotherapeutic trea tment of families of battered children. Developmental Medicine and Child Neurology, 16 (4), 447-456.

[24]. Peterson, L., Mullins, L. L., \& Ridley-Johnson, R. (1985). Childhood depression: Peer reactions to depression and life stress. Journal of Abnormal Child Psychology, 13, 597-609.

[25]. Puig-Antich, J., Lukens, E., Davies, M., Goetz, D., Brennan-Quattrock, J., \& Todak, G. (1985).

[26]. Psychosocial functioning in prepubertal major depressive disorders: I. Interpersonal relationships during the depressive episode. Archives of General Psychiatry, 23, 8-15

[27]. Radloff, L. S. (1977). The CES-scale: A self-report depression scale for research in the general population. Applied Psychological Measurement, 1, 385-401.

[28]. Riaz, M. N., \& Qasmi, F. N. (2012). Impact of Perceived of Parental Acceptance-Rejection on Psychological Adjustment and Self Concepts of Persons with Disabilities. Journal of Behavioural Sciences, 22, 64-82.

[29]. Rita, Z., \& Oksana, M. (2008). Personality and parental rearing practices as predictors of adolescent emotional and behavioral problems: Gender differences in predictive accuracy. Psichologija, 3, 63-83.

[30]. Robertson, J. F., \& Simons, R. L. (1989). Family factors, self-esteem, and adolescent depression. Journal of Marriage and the Family, 51, 125-138.

[31]. Rohner, R. P. (1986). The warmth dimension: Foundations of parental acceptance-rejection theory. Beverly Hills, CA: Sage Publications, Inc.

[32]. Rohner, R. P., Khaleque, A., \& Cournoyer, D. E. (2007). Parental acceptance-rejection theory, methods, and implications. In R. P. Rohner, \& A. Khaleque (eds.), Handbook for the study of parental acceptance and rejection (4th ed.). Retrieved from www.cspar.uconn.edu/Introduction-to-Parental-Acceptance

[33]. Rohner, R. P., \& Khaleque, A. (2005). Handbook for the study of parental acceptance and rejection. (4th ed.) Rohner Research Publications. Storrs, USA.

[34]. Rohner, P. R., \& Khaleque, A. (2002). Parental acceptance-rejection and life-span development: A Universal perspective. Retrieved from ww.ac.wwu.edu/ culture/Rohner_Khaleque.htm

[35]. Rothbaum, F., \& Weisz, J. R. (1994). Parental care giving and child externalizing behavior in non-clinical samples: A metaanalysis. Psychological Bulletin, 116, 55-74.

[36]. Sassaroli, S., \& Ruggiero, M. G., (2005). The role of stress in the association between low self-esteem, perfectionism, and worry, and eating disorders International Journal of Eating Disorders, 37(2), 135-141. doi: 10.1002/eat.20079

[37]. Savin-Williams, R. C. (1990). Adolescence: An ethological perspective. New York: Springer-Verlag.

[38]. Scott, W. A., Scott, R., \& McCobe, M. (1991). Family relationship and children personality: A cross-cultural, cross source comparison. British Journal of Social Psychology, 30, 1-20.

[39]. Sentse, M., Lindenberg, S., Omvlee, A., Ormel, J., \& Veenstra, R. (2009). Rejection and acceptance across contexts: parents and peers as risks and buffers for early adolescent psychopathology. Journal of Abnormal Child Psychology, 38(1), 119-130.

[40]. Simons, R. L., Robertson, J. F., \& Downs, W. R. (1989). The nature of the association between parental rejection and delinquent behavior. Journal of Youth and Adolescence, 18, 297-310.

[41]. Wells J, Barlow J, Stewart-Brown S. (2001). A systematic review of universal approaches to mental health promotion in schools. Oxford, UK: Health Services Research Unit, University of Oxford.

[42]. Wichstro^m, L., Anderson, A. M. C., Holte, A., \& Wynne, L. C. (1996). Disqualifying family communication and childhood social competence as predictors of offspring's mental health and hospitalization: A 10- to 14-year longitudinal study of children at risk of psychopathology. Journal of Nervous and Mental Disease, 184, 581-588.

[43]. Yoshizumi, T., Murase, S., Murakami, T., \& Takai, J. (2007). Dissociation as a mediator between perceived parental rearing style and depression in an adult community population using college students. Personality and Individual Differences, 43, 353-364.

[44]. Zhe, C., Mei, P. Y., Rong, C., \& Shi-jie, Z. (2011). The relationship among childhood abuse, parenting styles and antisocial personality disorder tendency. Chinese Journal of Clinical Psychology, 19(2). 